\title{
AGRICULTURA URBANA:
IDENTIFICAÇÃO DE OPORTUNIDADES DE PROJETO PARA O PROCESSO PRODUTIVO E COMERCIALIZAÇÃO
}

\section{Diego Costa, Mestrando (UFRJ); \\ Carla Cipolla, Dra. (UFRJ);}

\begin{abstract}
PALAVRAS CHAVE
Desenvolvimento Sustentável; Design de Produtos; Design de Serviços; Agricultura Urbana
\end{abstract}

KEY WORDS

Sustainable Development; Product Design; Design Services; Urban Agriculture

\section{RESUMO}

O artigo define as características específicas da agricultura urbana (AU) por meio de uma revisão da literatura e aponta quais os principais aspectos da $\mathrm{AU}$ a serem considerados no desenvolvimento de novos produtos e serviços. $\mathrm{O}$ processo envolve a análise das atividades realizadas pelo Centro de Educação Multicultural (CEM) que desenvolve agricultura urbana no complexo de favelas da Penha, na cidade do Rio de Janeiro.

\section{ABSTRACT}

The article defines the specific characteristics of urban agriculture (UA) through a literature review and points out the main aspects of the UA to be considered in the development of new products and services. The research process includes the analysis of the activities developed by the the NGO called Multicultural Education Center (CEM) which promotes urban agriculture in a slum (known as Complexo da Penha) in the city of Rio de Janeiro. 


\section{INTRODUÇÃO}

Até o ano de 2050 a população mundial passará de pouco mais de 7 bilhões para 9 bilhões de pessoas, dos quais dois terços viverá em cidades (ONU, 2015). Ainda segundo a ONU (2014), em 2030, as megalópoles - cidades com mais de 10 milhões de habitantes - passarão de 28 para $41 \mathrm{em}$ todo mundo, o que aumentará de forma drástica as demandas por acesso a saúde, educação, habitação, saneamento básico, emprego, entre outros. Tal quadro constitui um grande desafio, sendo necessárias soluções que promovam um desenvolvimento sustentável das cidades. Alinhado com esta demanda, o presente trabalho focaliza-se em uma atividade cada vez mais presente nestes contextos: a agricultura urbana.

A agricultura urbana (AU) tem crescido significativamente durante as últimas duas décadas. Ela é cada vez mais aceita e utilizada como uma ferramenta no desenvolvimento sustentável na medida em que, onde se estabelece com eficiência, desempenha um papel muito importante na alimentação das populações (FAO, 1999). O processo de urbanização acelerado faz crescer a demanda por melhores oportunidades e melhor qualidade de vida e é justamente neste sentido que a AU traz uma oportunidade de revalorização dos espaços urbanos como áreas destinadas à produção de alimentos, à geração de renda, à reaproximação com a natureza, ao lazer, ao convívio, etc. São diversas as experiências em todo mundo que demonstram como a AU pode contribuir na melhoria da qualidade de vida das famílias e comunidades (FAO, 2014; Arruda, 2011; Henk, 2008).

$\mathrm{O}$ lançamento de produtos voltados para a $\mathrm{AU}$ vem ganhando escala nos últimos anos e contribui diretamente com a promoção e ampliação da AU e o consequente desenvolvimento sustentável das cidades. Além disso, esse é um nicho de mercado com grande potencial econômico, gerador de renda e emprego não só para quem pratica a $\mathrm{AU}$, mas também para quem projeta, produz e vende produtos para a AU (Vickery, 2014).

Este artigo investiga oportunidades de projeto para melhorar o processo produtivo e de comercialização dos produtos oriundos da AU. Para isso, foi conduzido um estudo de caso no Centro de Educação Multicultural (CEM), uma ONG que faz o reflorestamento e plantio de alimentos em uma área urbana de recuperação ambiental no subúrbio da cidade do Rio de Janeiro. Por meio da análise das demandas da ONG foi investigado quais os principais requisitos e demandas de projeto de produtos e serviços no CEM.

\section{PROCEDIMENTOS METODOLÓGICOS}

Este artigo refere-se a um estudo de caso e tem caráter qualitativo. Para o estudo foram realizados os seguintes procedimentos metodológicos: (1) Revisão da literatura, que fundamentou o entendimento de agricultura urbana, contribuiu na estruturação do estudo de caso e gerou parâmetros para avaliação dos dados coletados; (2) na coleta de dados, que foi realizada por meio de entrevistas semiestruturadas, observação indireta e observação participante; (3) Análise dos dados obtidos.

Para adquirir conhecimento das questões relativas à agricultura urbana e as suas características, foi realizada uma revisão narrativa da literatura, que, segundo Rother (2007), é apropriada para descrever e discutir o desenvolvimento de questões mais amplas. A revisão narrativa também foi utilizada no levantamento das questões ligadas ao design de produtos e serviços.

A coleta de dados para o estudo de caso foi realizada na sede do Centro de Educação Multicultural e durou aproximadamente um mês. Foram realizadas três entrevistas semiestruturadas com os responsáveis pela execução do projeto de agricultura urbana da ONG. As entrevistas tiveram como objetivo de entender suas definições sobre a agricultura urbana e quais as dificuldades enfrentadas no trabalho diário com a horta urbana.

Ainda na coleta de dados foi conduzida uma observação participante, onde o pesquisador experimenta na prática o cotidiano do pesquisado, e uma observação indireta. A observação participante aconteceu no período de dois dias e foram escolhidos os dias de colheita e venda dos produtos, uma sexta e sábado respectivamente. A observação indireta, onde o pesquisador observa o pesquisado sem que haja interação com ele, foi realizada no período de uma semana de trabalho, de segunda à sábado. Os dois tipos de observação foram realizadas em períodos diferentes para que uma não comprometesse a outra. A análise dos dados foi realizada comparando-se as características da agricultura urbana descritas na revisão da literatura com as características encontradas no estudo de caso. Também foi feito um levantamento das novas possibilidades projetuais no setor da agricultura urbana, utilizando o estudo de caso como exemplo, e tendo como foco específico a atividade de design de produtos e serviços.

\section{AGRICULTURA URBANA E SUAS CARECTERÍSTICAS}

A Apesar da AU ser um tema cada vez mais frequente em organizações como a ONU, UNESCO, governos, empresas 
privadas, redes, associações, entre outros, ainda não existe um consenso sobre sua definição. A grande diversidade de cidades e seus entornos contribuem para este fato.

Para a FAO (2007) a agricultura urbana é aquela que é praticada dentro e no entorno das cidades (regiões periurbanas). Essa AU gera produtos oriundos da agricultura, pecuária, pesca e silvicultura. Inclui também produtos florestais não madeireiros, bem como serviços ecológicos prestados pela agricultura, pesca e silvicultura. Ainda segundo a $\mathrm{FAO}$, uma única cidade pode possuir inúmeros serviços e sistemas de agricultura.

Mougeot (2000) acredita que o que distingue a agricultura rural da agricultura urbana é a integração que a AU possui com o sistema ecológico e econômico das cidades. Sendo assim, iniciativas intraurbanas e periurbanas onde não aconteça essa interação não seriam consideradas AU. Essa definição é útil principalmente quando estamos tratando da agricultura que ocorre em áreas periurbanas, cuja localização nas cercanias da cidade não garante a interação com o ecossistema urbano. Na figura 01 são representados os elementos que interagem com a agricultura urbana, dentro e fora das zonas urbanas

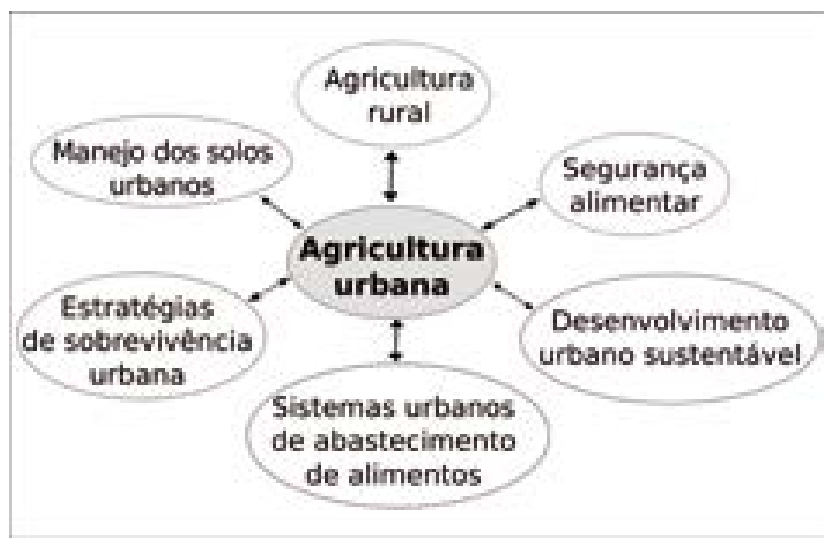

Fonte: Adaptado de Mougeot (2002)

A definição de Veenhuizen (2006) engloba tanto a produção voltada para comercialização quanto para o autoconsumo. Ele define AU como o crescimento de plantas e criação de animais para usos alimentares e não alimentares nas cidades e ao redor delas, incluindo atividades como processamento e venda de produtos.

Mougeot (2000) apresenta seis principais elementos que, segundo ele, caracterizam a AU, são eles: os tipos de atividades econômicas; as categorias e subcategorias de produtos; a localização da atividade; os tipos de áreas onde é praticada; o destino dos produtos; os tipos de sistemas de produção e a escala de produção. Tais elementos são detalhados a seguir:

- Os tipos de atividades econômicas: na agricultura convencional a produção rural geralmente não interage, ou interage pouco, com o beneficiamento e venda dos produtos. $\mathrm{O}$ mesmo não ocorre na $\mathrm{AU}$, onde as atividades de produção, beneficiamento e venda, são próximas e intimamente interligadas no espaço urbano. $\mathrm{Na} \mathrm{AU}$ a cadeia de produção é baseada em pequenas unidades, geralmente descentralizadas e em contato direto com o mercado consumidor;

- As categorias e subcategorias de produtos: os produtos provenientes da AU podem ser de origem animal ou vegetal, incluindo produtos para alimentação (grãos, vegetais, hortaliças, etc.) e produtos não alimentícios (ervas aromáticas, tabaco, plantas ornamentais, etc). Alguns autores consideram apenas os produtos alimentícios, o que segundo Mougeot (2002) limitaria a análise da capacidade produtiva da AU como um todo. Ainda em decorrência da interação direta com o meio urbano, a AU conta com uma maior capacidade de produzir produtos e serviços que interajam com a cidade, o que aumenta o leque de produtos (e serviços) oriundos desta modalidade de agricultura;

- A localização da atividade: a agricultura urbana pode estar localizada no ambiente intraurbano e no periurbano. O ambiente periurbano, mesmo sendo constituído pela área ao entorno das cidades, classifica este tipo de agricultura como urbana pois esta sofre muitas influências do ambiente urbano e apresenta uma proximidade que permite uma grande interação com as cidades;

- Os tipos de áreas onde é praticada: estas áreas variam de acordo com sua localização respectiva em relação a moradias, modalidades de posse e/ou usufruto do local, a classificação da área onde a terra é utilizada (industrial, residencial, comercial, pública, etc.), entre outros;

- O destino dos produtos: os produtos da AU são destinados tanto ao autoconsumo quanto à venda. As duas categorias têm importância econômica. A produção para consumo pode representar a segurança alimentar de famílias que estão em áreas de "deserto alimentar" (áreas que apesar de estarem em cidades não possuem mercados que vendam alimentos de valor nutricional relevante ou saudáveis);

\section{- Os tipos de sistemas de produção e a escala de produção:} as definições de AU não excluem os diferentes tipos de sistemas de produção e escala. São encontrados casos de AU em nível individual, familiar, coletivo, empresarial, etc. A produção em AU é diversificada, sendo mais comum a realizada em pequena escala, apesar de também serem encontrados casos de produção com escalas consideráveis. De qualquer forma, a produção é sempre orientada aos mercados locais. 


\section{O CENTRO DE EDUCAÇÃO MULTICULTURAL NAAU}

O Centro de Educação Multicultural (CEM) é uma organização não governamental (ONG) localizada no Complexo de favelas da Penha, zona norte do Rio de Janeiro. A sede da organização fica na comunidade do Grotão, ao pé da Serra da Misericórdia, que é um maciço que abrange aproximadamente 27 bairros do subúrbio carioca e, desde o ano 2000, é uma Área de Proteção Ambiental e Recuperação Urbana.

O CEM foi fundado no ano de 2011 com uma proposta de ação multicultural na comunidade do Grotão e adjacências. Na ONG são realizadas diversas atividades como capoeira, teatro, cursos de grafite, acolhimento comunitário, entre outras. Uma das atividades realizadas pela ONG é o reflorestamento da Serra da Misericórdia, constituído através do plantio de uma agrofloresta, sendo esta caracterizada como um consórcio de árvores nativas com plantas alimentícias (verduras, hortaliças, tubérculos, etc.). A produção de plantas alimentícias no espaço urbano e a interação da ONG com a comunidade (o ecossistema urbano) são os elementos que caracterizam tal iniciativa como agricultura urbana.

A escolha em reflorestar com plantio de alimentos foi tomada pois, se tratando de um ambiente de vulnerabilidade social, a produção de alimento é uma forma de gerar renda e garantir a segurança alimentar dos moradores. Esta foi a principal estratégia de aproximação com a comunidade que, no seu envolvimento no plantio ou apenas no consumo dos alimentos, também é educada sobre importância da preservação e recuperação das áreas verdes da Serra da Misericórdia. Desta forma, o CEM, além de produzir alimentos, também funciona como um centro de educação ambiental e multiplicação de biodiversidade na comunidade. Hoje, além dos moradores que buscam informações individualmente, a ONG também atende à escolas e creches, realizando aulas de educação ambiental, passeios pela Serra da Misericórdia, oficinas, workshops, acompanhamento técnico na implantação de hortas, entre outras atividades.

\subsection{Observação indireta}

Tendo como objetivo a compreensão da dinâmica de trabalho semanal da ONG, conduziu-se uma observação indireta das atividades realizadas ao longo de uma semana. A observação deu-se da seguinte forma: o pesquisador acompanhava a rotina diária do CEM, com o mínimo de interação possível e, conforme as atividades eram realizadas, preenchia uma tabela relatando as mesmas. Foram seis dias de observação, de segunda à sábado, e, em média, foram anotadas 19 atividades distintas durante cada dia. As atividades eram bem diversificadas e incluíam desde a preparação do almoço e limpeza do espaço à plantio de mudas e passeio com turmas escolares pela Serra. A tabela 1 apresenta as quatro principais atividades realizadas nos dias de pesquisa. Principais apontamentos da observação indireta:

- Durante a observação indireta todos os dias começaram com uma reunião de esclarecimento e ajustes do que deveria ser feito naquele dia.

- Algumas atividades tinham recorrência diária, são elas: preparo do almoço, limpeza da cozinha, alimentação dos animais e rega das plantas.

- A rega das plantas é manual e dura em média duas horas e meia, por isso foi incluída no grupo de principais atividades realizadas.

- A venda na feira acontece em barraca alugada pelo CEM.

- A limpeza do terreno é dificultada devido a inclinação do local. O mesmo ocorre ao capinar as áreas plantadas. Ainda quanto à capina, ela acontece tanto manualmente, com tesoura de poda, quanto com roçadeira à gasolina.

- A ida ao CEASA é feita utilizando-se transporte público. Os alimentos comprados são transportados em carrinho semelhante ao utilizado para transportar engradados de cerveja.

- A produção dos desidratados (banana e tomate) inclui: lavagem e sanitização, descascamento, desidratação, separação por peso e ensacamento.

- O plantio das mudas acontece com frequência e é atividade fundamental para o reflorestamento e para a produção de alimentos.

- A educação ambiental com alunos da escola incluiu plantio de mudas e passeio pela Serra.

- O manejo dos viveiros é feito para desmamar as mudas que criam raízes no chão e organizar as que irão para feira.

- A colheita para a comercialização em feira ocorre no final do 
dia na sexta-feira e inclui colher e separar as porções para venda. - A ida para a feira ocorre de ônibus, os produtos são transportados em um simples carrinho, semelhante ao utilizado para transporte de engradados de cerveja, sendo este empregado

Tabela 01 - Principais atividades realizadas durante a semana

\begin{tabular}{|c|c|c|c|c|c|}
\hline Segunda-feira & Terça-feira & Quarta-feira & Quinta-feira & Sexta-feira & Sábado \\
\hline $\begin{array}{l}\text { Limpeza da sede e } \\
\text { do terreno }\end{array}$ & Ida à CEASA & Plantio de mudas & Plantio de mudas & Manejo de viveiros & Ida para a feira \\
\hline Capinar o terreno & $\begin{array}{l}\text { Produçalo de } \\
\text { dessidratados }\end{array}$ & $\begin{array}{l}\text { Produçẫo de } \\
\text { desidratados }\end{array}$ & $\begin{array}{c}\text { Educacaio } \\
\text { ambiental com } \\
\text { alunos de escola }\end{array}$ & $\begin{array}{c}\text { Colheita para a } \\
\text { feira }\end{array}$ & $\begin{array}{c}\text { Venda de } \\
\text { produtos na feira }\end{array}$ \\
\hline $\begin{array}{l}\text { Alimentar } \\
\text { animais }\end{array}$ & $\begin{array}{l}\text { Alimentar } \\
\text { animais }\end{array}$ & $\begin{array}{l}\text { Alimentar } \\
\text { animais }\end{array}$ & $\begin{array}{l}\text { Alimentar } \\
\text { animais }\end{array}$ & $\begin{array}{l}\text { Alimentar } \\
\text { animais }\end{array}$ & $\begin{array}{l}\text { Alimentar } \\
\text { animais }\end{array}$ \\
\hline Molhar as plantas & Molhar as plantas & Molhar as plantas & Molhar as plantas & Molhar as plantas & Molhar as plantas \\
\hline
\end{tabular}

Fonte: Autores

igualmente para outras atividades de transporte.

\subsection{Observação participante}

A observação participante, na qual o pesquisador vivência na prática as atividades, foi conduzida em uma semana diferente da observação indireta para que não houvesse interferência na pesquisa. Os dias escolhidos foram sexta e sábado, sendo o primeiro o dia da colheita e preparação para a feira orgânica, e o segundo o dia da venda dos produtos na feira.

Com objetivo de vivenciar na prática a rotina dos pesquisados, a observação participante foi um instrumento de aproximação pessoal do pesquisador com as atividades do CEM. Não houve uma documentação das atividades realizadas durante o dia, sendo essa apenas produzida em forma de relato ao final dos dois dias de trabalho.

Durante a processo foram vivenciadas algumas dificuldades que complementaram os achados da observação indireta: o transporte dos produtos enquanto eles são colhidos e separados é complicado, pois o terreno é inclinado e isso atrapalha a movimentação; a locomoção da sede da ONG até a feira não é fácil, principalmente por se precisar carregar os produtos em carrinho semelhante aos de engradados de cerveja, o que torna subir no ônibus uma tarefa penosa; durante a feira não há lugar para sentar, o que deixa o trabalho cansativo.

Nos dois dias de observação direta foi interessante per- ceber como a agricultura urbana está conectada com a comunidade. São vários os moradores que aparecem para conversar e acabam ajudando nas atividades da ONG. Outro aspecto interessante é que, por estar em um centro urbano, o CEM está diretamente conectado com seus parceiros e clientes, as ligações telefônicas são constantes e o uso da internet para fins de comunicação parece ser indispensável. Apesar de se localizar próximo à feira, o uso de transporte público foi fundamental, pois seria complicado carregar o carrinho de produtos pelas ruas e calçadas sem conservação do bairro.

\section{O DESIGN DE PRODUTOS PARA A AGRICULTURA URBANA}

$A$ atividade de desenvolvimento de um produto ou serviço implica no conhecimento profundo das características e necessidades do contexto para o qual se está projetando. Projetar é, de maneira resumida, coletar dados para analisá-los e, posteriormente, sintetizar todo o conhecimento adquirido na forma de um novo produto ou serviço.

Para se desenvolver soluções para a AU não se deve deixar de considerar os seus seis principais elementos específicos que, segundo Mougeot (2000), caracterizam a $\mathrm{AU}$ e que foram detalhados anteriormente neste artigo: os tipos de atividades econômicas; as categorias e subcategorias de produtos; a localização da atividade; os tipos de 
áreas onde é praticada; o destino dos produtos; os tipos de sistemas de produção e a escala de produção.

Confrontando essas características com a realidade encontrada no estudo de caso, foi possível identificar alguns aspectos específicos e oportunidades de projeto para a produção e comercialização dos produtos da AU:

1 - No CEM as atividades de produção, beneficiamento e venda dos produtos estão conectadas e são realizadas pela própria ONG. A cadeia de produção é sempre curta, o que facilita o transporte entre a colheita e a venda. $\mathrm{Na}$ observação direta, no entanto, este transporte se mostrou dificultado pelas particularidades das ruas e calçadas da região. A adaptação de um carrinho de transporte de engradados de cerveja em um carrinho para transportar vegetais não foi adequada. Em termos projetuais podemos observar que toda a cadeia de transporte de alimentos na agricultura urbana é uma oportunidade de inovação.

2 - A interação com os consumidores é intensa. O desenvolvimento de novos produtos e serviços que estimulem o contato direto entre consumidor e produtor podem aumentar os ganhos do produtor, que passa a vender mais e com melhor preço, e os benefícios para o consumidor, que consome um alimento mais fresco e de origem conhecida e verificável.

3 - A área de plantio do CEM é toda em terreno inclinado. Essa é uma dificuldade no momento de plantar, manejar e realizar a colheita. Ferramentas e equipamentos voltados para esse tipo de produção podem facilitar a realização das tarefas.

4 - A produção do CEM é uma produção de pequena/ média escala, o que já justificaria a automatização de diversas tarefas como, por exemplo, a irrigação do terreno, a alimentação dos animais, o sistema de bombas d'água, a produção dos desidratados, entre outros. Muitas soluções já foram pensadas nesse sentido quando se trata de agricultura rural, mas pouco foi feito especificamente para a AU. Novos projetos devem considerar sempre as facilidades urbanas como acesso à internet, rede de telefonia, vizinhos morando nas proximidades, etc. Todos esses são insumos para inovação em projetos de AU.

5 - Estar localizado no centro urbano também aproxima o CEM dos centros tecnológicos. Eles são importantes áreas de inovação e pesquisa. Muitos estudantes universitários de diversas faculdades visitam e demonstram interesse pelas atividades realizadas no CEM, neste sentido a agricultura urbana pode se tornar um importante laboratório para inovações que posteriormente possam ser implementadas também na agricultura convencional.

\section{CONCLUSÃO}

Este artigo aborda o caso de agricultura urbana praticada no CEM. Entretanto esta constitui-se apenas como um tipo possível de $\mathrm{AU}$, dentre vários outros possíveis. Como foi evidenciado na revisão bibliográfica, a agricultura urbana é tão diversa e complexa quanto o tecido social urbano. Ela, portanto, é múltipla e possui diferentes objetivos. O que se deve deixar claro, porém, é que independente dos tipos de AU e objetivos desejados com sua prática, esta encontra-se invariavelmente ligada ao desenvolvimento sustentável das cidades.

$\mathrm{O}$ artigo explicita que a AU é um campo vasto para o desenvolvimento de novos produtos e serviços. A agricultura praticada nas cidades quebra com uma série de paradigmas existentes na agricultura rural. $\mathrm{O}$ contato direto com o consumidor, o proximidade dos centros de distribuição, o acesso a serviços de internet, telefonia, transporte público, aos centros de pesquisa, o fácil acesso à novas tecnologias, entre outros, são apenas alguns exemplos de como agricultura urbana é diferente da agricultura rural. Ao se desenvolver produtos (e serviços) essas diferenças precisam ser consideradas, elas trazem consigo novas possibilidades projetuais que fazem da AU um campo fértil para inovação. Outros estudos com diferentes iniciativas de AU devem ser realizados para que seja ampliado o conhecimento de como o design de produtos e serviços pode contribuir no desenvolvimento deste tipo de agricultura.

\section{REFERÊNCIAS}

\section{Arruda, J. - Agricultura Urbana na Região Metropo-} litana do Rio de Janeiro. Tese de doutorado. UFFRJ . 2011.

\section{FAO - Growing greener cities in Latin America and} the Caribbean. An FAO report on urban and peri-urban agriculture in the region. ed. FAO Newsroom. 2014.

3. FAO - Farming in urban areas can boost food security. FAO Newsroom. 2005. 4. FAO - Growing Greener Cities in Latin America and the
Caribbean. FAO Newsroom. 2014.

5. Henk, R. - Thematic paper 3: Innovative experiences 
with multifunctional urban and peri-urban agriculture in city regions in the global South. RUAF Foundation. 2008.

6. IDSA - What is Industrial Design?. Industrial Designers Society of America. Disponível em: <http://www. idsa.org/>. Acesso em 03/12/2015.

7. Mougeot, J. A. - Urban Agriculture: Definition, Presence, Potentials and Risks, and Policy Challenges. International Development Research Centre (IDRC). 2000.

8. ROTHER, E. T. - Revisão sistemática X Revisão Narrativa. Acta Paul Enferm. 2007.

9. ONU - World Urbanization Prospects. UN. 2014.

10. ONU - World Urbanization Prospects. UN. 2015.

11. VEENHUIZEN, R. - Cities farming for the future; Urban Agriculture for green and productive cities. RUAF Foundation. 2006.

12. VICKERY, K. Barriers to and Opportunities for Commercial Urban Farming: Case Studie from Austin, Texas and New Orleans, Louisiana. The University of Texas at Austin. 2014. 